\title{
Synthesis and Antimicrobial Activity of Azole Derivatives
}

\author{
Talapuru Bhanu Prakash, Lingaladinne Mallikarjuna Reddy, Adivireddy Padmaja, and \\ Venkatapuram Padmavathi*
}

Department of Chemistry, Sri Venkateswara University; Tirupati 517 502, Andhra Pradesh, India.

Received November 6, 2012; accepted February 27, 2013

\begin{abstract}
A new class of mono and bis heterocycles, sulfonylmethaneamido linked oxazoles, thiazoles, imidazoles, pyrrolyl oxazoles, pyrrolyl thiazoles and pyrrolyl imidazoles were prepared adopting simple and versatile synthetic methodologies. The compound chloro substituted imidazolyl styrylsulfonylacetamide is the most potent antimicrobial agent particularly against Pseudomonas aeruginosa and Penicillium chrysogenum.
\end{abstract}

Key words oxazole; thiazole; imidazole; pyrrole; antimicrobial activity

The ubiquity of azoles in a wide variety of naturally occurring and synthetic molecules and their pivotal role as synthetic intermediates has attracted the attention of both industrial and academic communities. In particular mixed $\mathrm{N}, \mathrm{S}$ - or $\mathrm{N}, \mathrm{O}$ heterocycles such as thiazoles and oxazoles are thiopeptide antibiotics $^{1,2)}$ and are recognized as signature metal binding sites common to clinically important macrocyclic peptides i.e., Bistratamides, ${ }^{3)}$ Didmolamides, ${ }^{4)}$ Lyngbyabellin, Calyculins $^{5,6)}$ and show cytotoxic, antimicrobial and multiple drug resistance activities. Imidazole-based drugs such as $\mathrm{Ci}$ metidine, Etomidate and Ketoconazole are currently in clinical use. ${ }^{7)}$ The Hantzsch reaction of $\alpha$-halocarbonyl compounds with thioureas or thioamides is the most commonly used method for the synthesis of thiazoles. ${ }^{8,9)}$ Methods for the synthesis of substituted oxazoles include Robinson-Gabriel synthesis of cyclodehydration of $\alpha$-acylaminocarbonyl compounds, ${ }^{10-15}$ ) the Cornforth and Cornforth method, ${ }^{16)}$ improved by Yokoyama, ${ }^{17,18)}$ the Hantzsch-type reaction of $\alpha$-halo/acyloxy carbonyl compounds with amides ${ }^{19)}$ dehydrative cyclization of $\beta$-hydroxy amides followed by oxidative dehydrogenation ${ }^{19-26)}$ and pyrolysis of $\alpha$-acylisoxazolones. ${ }^{27)}$ The synthesis of imidazoles was first reported by Radziszewski reaction from glyoxal, formaldehyde and ammonia. ${ }^{28)}$ Apart from these, pyrroles constitute the core unit of many natural products and serve as building blocks for porphyrin synthesis. ${ }^{29,30)}$ Members of this family have wide applications in medicinal chemistry, being used as antimalarial, antiinflammatory, antibacterial and antiviral agents. ${ }^{31-33)}$ Many synthetic methods have been employed for the synthesis of pyrroles including Knorr, ${ }^{34)}$ PaalKnorr, ${ }^{35-37)}$ Hantzsch synthesis, ${ }^{38)}$ 1,3-dipolar cycloaddition reactions, ${ }^{39)}$ reductive coupling ${ }^{40)}$ and aza-Wittig reactions. ${ }^{41)}$ Recently, we have studied the antimicrobial activity of amido linked pyrrolyl and pyrazolyl oxazoles, thiazoles and imidazoles and identified imidazolyl cinnamamide as potential antimicrobial agent. ${ }^{42}$ Motivated by the aforesaid findings, herein we report on the preparation and antimicrobial assay of some new sulfonylmethaneamido linked heterocycles using a simple synthetic approach from easily accessible building blocks.

Chemistry For the synthesis of bis heterocycles mentioned in the scheme, the compounds 4-aryloxazol-2-amine ${ }^{43}$ (1), 4-arylthiazol-2-amine ${ }^{43)}$ (2), 4-aryl-1 $H$-imidazol-2-amine ${ }^{44)}$ (3) and $Z$-(arylethenesulfonyl)acetic acid $^{45)}$ required as the starting materials were prepared by adopting the literature

The authors declare no conflict of interest. precedent. The Z-(arylethenesulfonyl)acetyl chloride (4) was prepared by the chlorination of $Z$-(arylethenesulfonyl)acetic acid with thionyl chloride. The heteroaryl $Z$-styrylsulfonylmethane amides, Z-(2-arylethenesulfonyl)- $N$-(4-aryloxazol-2yl)acetamide (5), Z-(2-arylethenesulfonyl)- $N$-(4-arylthiazol-2yl)acetamide (6), and $Z$-(2-arylethenesulfonyl)- $N$-(4-aryl- $1 H$ imidazol-2-yl)acetamide (7) were obtained by the reaction of $\mathbf{1}, \mathbf{2}$, and $\mathbf{3}$ with $\mathbf{4}$. The ${ }^{1} \mathrm{H}-\mathrm{NMR}$ spectra of $\mathbf{5 a}, \mathbf{6 a}$, and $7 \mathbf{a}$ showed two singlets at $\delta 7.30,6.34,7.28$, and 4.25, 4.22, $4.25 \mathrm{ppm}$ due to $\mathrm{C}_{5}-\mathrm{H}$ and methylene protons flanked between $\mathrm{CO}$ and $\mathrm{SO}_{2}$ groups. A broad singlet was observed at 7.95, 7.91 and $7.92 \mathrm{ppm}$ due to NH. The compound 7a showed another broad singlet at $12.26 \mathrm{ppm}$ due to $\mathrm{NH}$ of imidazole ring. The signals of $\mathrm{NH}$ disappeared on deuteration. In addition, two doublets were observed at $\delta 7.16,7.13,7.14$, and 6.47, $6.46,6.47 \mathrm{ppm}$ which were accounted for olefin protons, $\mathrm{H}_{\mathrm{A}}$ and $\mathrm{H}_{\mathrm{B}}$, respectively. The coupling constant value $J \approx 9.3 \mathrm{~Hz}$ indicated that they possess cis geometry. The olefin moiety present in these compounds was used to develop pyrrole ring. Thus, the 1,3-dipolar cycloaddition of tosylmethyl isocyanide to $\mathbf{5}, \mathbf{6}$ and 7 in the presence of sodium hydride in ether and dimethyl sulfoxide (DMSO) led to bis heterocycles, Z-(4'aryl-1' $H$-pyrrol-3'-ylsulfonyl)- $N$-(4-aryloxazol-2-yl)acetamide (8), Z-(4'-aryl-1' H-pyrrol-3'-ylsulfonyl)- $N$-(4-arylthiazol-2-yl)acetamide (9), and $Z$-(4'-aryl-1' $H$-pyrrol-3'-ylsulfonyl)- $N$-(4aryl-1H-imidazol-2-yl)acetamide (10) (Chart 1).

The ${ }^{1} \mathrm{H}-\mathrm{NMR}$ spectra of $\mathbf{8 a}, \mathbf{9 a}$ and $\mathbf{1 0 a}$ displayed two singlets at $\delta 6.82,6.79,6.80$ and $6.73,6.70,6.71 \mathrm{ppm}$ due to $\mathrm{C}_{2^{\prime}}-\mathrm{H}$ and $\mathrm{C}_{5}, \mathrm{H}$ respectively, in addition to the signals of methylene protons, $\mathrm{C}_{5}-\mathrm{H}$ and $\mathrm{NH}$. The structures of all the compounds were further established by IR, ${ }^{13} \mathrm{C}-\mathrm{NMR}$ and elemental analyses.

In-Vitro Antimicrobial Study The compounds 5-10 were screened for antimicrobial activity at four different concentrations, 12.5, 25, 50, and $100 \mu \mathrm{g} /$ well. Investigation of antibacterial screening data depicted in Table 1 and Fig. 1 showed that Gram-negative bacteria were more susceptible towards the tested compounds than Gram-positive ones. It was observed that the compounds $7 \mathbf{c}$ and 10c were effective particularly against Pseudomonas aeruginosa at the tested concentrations when compared with the standard drug Chloramphenicol. It was also observed that mono heterocyclic compound with styryl moiety 7 exhibited slightly higher activity than the corresponding bis heterocyclic compound $\mathbf{1 0}$. Amongst bis heterocyclic compounds 8-10, those with pyrrole 


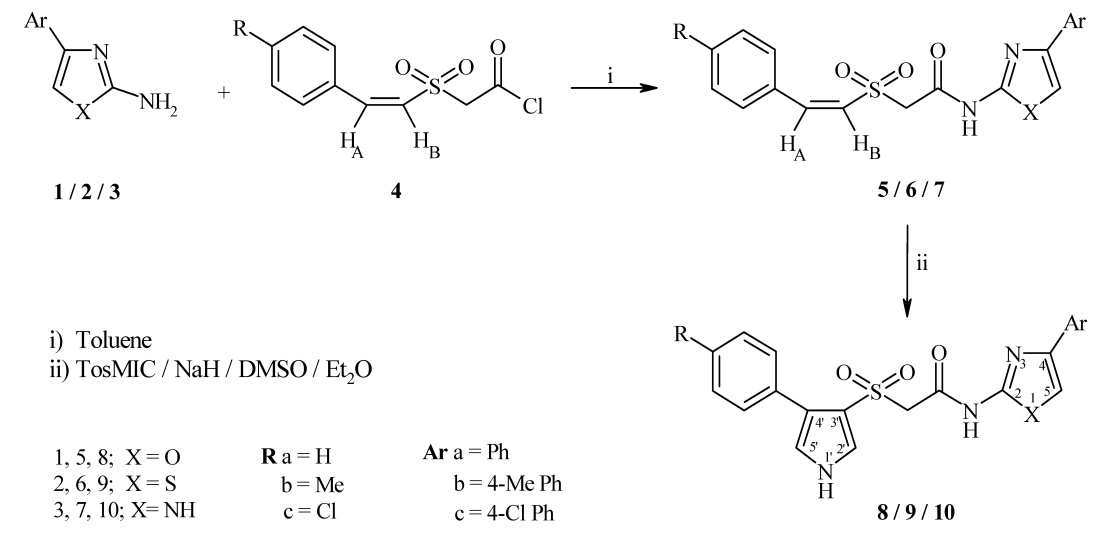

Chart 1

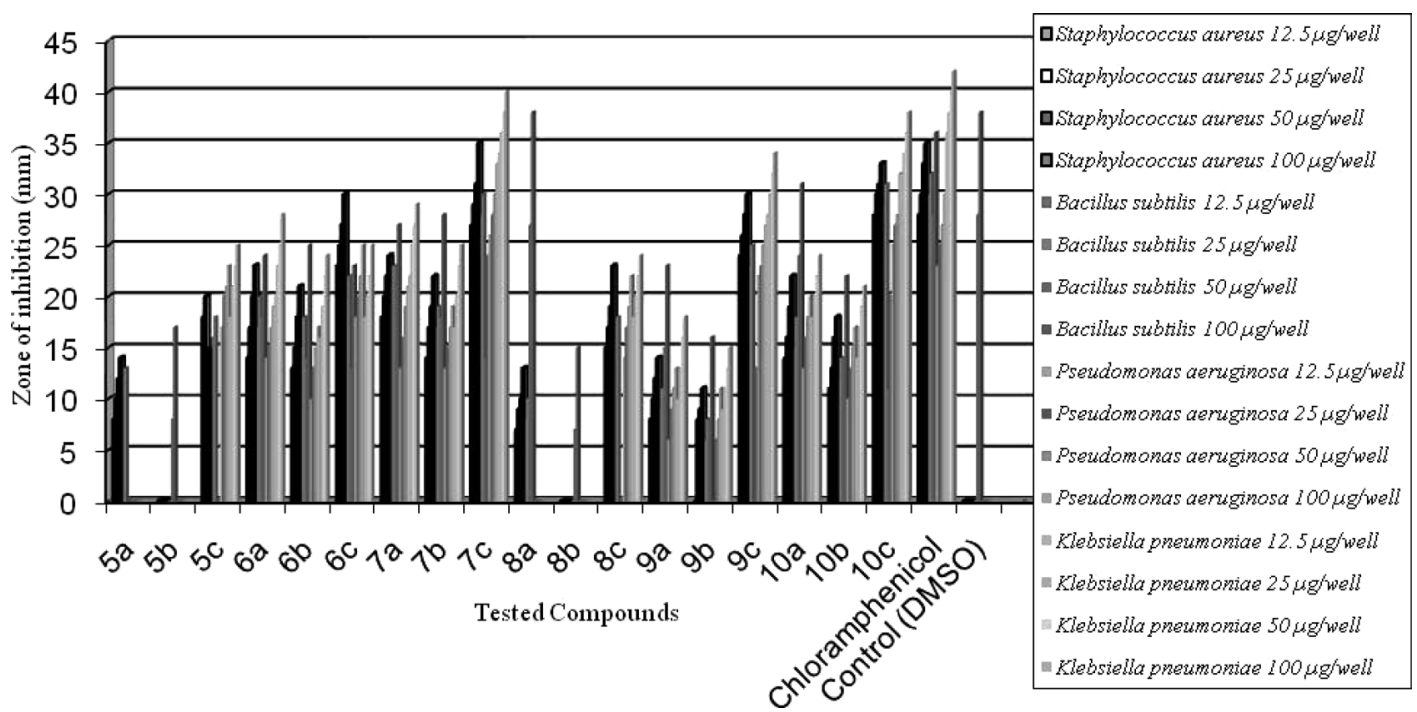

Fig. 1. The in-Vitro Antibacterial Activity of Compounds 5-10

in combination with imidazole (10) displayed greater activity than the compounds having pyrrole and oxazole $(\mathbf{8})$ or thiazole (9). However, the compounds $\mathbf{6 c}$ and $9 \mathbf{c}$ exhibited moderate activity. On the other hand, the compounds $\mathbf{5}$ and $\mathbf{8}$ displayed least activity. The presence of chloro substituent on the aromatic ring enhances the activity.

All the tested compounds inhibited the spore germination against tested fungi except $\mathbf{5 a}, \mathbf{5 b}, \mathbf{8 a}$, and $\mathbf{8 b}$. In general, most of the compounds showed slightly higher antifungal activity towards Penicillium chrysogenum than Aspergillus niger. The compounds $\mathbf{7 c}$ and $\mathbf{1 0 c}$ exhibited excellent activity particularly against Penicillium chrysogenum almost equivalent to the standard drug Ketoconazole. However, the compounds $\mathbf{6 c}$ and $9 \mathbf{c}$ displayed moderate inhibition against the tested fungi (Table 2, Fig. 2).

The minimum inhibitory concentration (MIC), minimum bactericidal concentration $(\mathrm{MBC})$ and minimum fungicidal concentration (MFC) values of the tested compounds are listed in Table 3. The compound 7c exhibited low MIC values when compared with 10c. Besides, the MBC value is $2 \times \mathrm{MIC}$ in case of Bacillus subtilis and Pseudomonas aeruginosa and MFC value is $2 \times \mathrm{MIC}$ in case of Penicillium chrysogenum. On the other hand, compound 10c displayed bactericidal and fungicidal effects greater than $2 \times$ MIC. It was observed that mono heterocyclic compounds (5-7) are slightly more potent than bis heterocyclic systems $(\mathbf{8}-\mathbf{1 0})$. This may be due to the presence of styrylsulfonyl moiety in mono heterocyclic compounds. Further, imidazole analogues $(7,10)$ are more potent than oxazole or thiazole analogues $(\mathbf{5}, \mathbf{6}, \mathbf{8}, \mathbf{9})$. It was also observed that 4-chlorophenyl analogues are more potent than unsubstituted phenyl or 4-methylphenyl analogues. In continuation of our earlier work, ${ }^{42)}$ it was inferred that sulfonylmethaneamido linked heterocycles displayed greater activity than amido linked bis heterocycles. Thus the presence of sulfonylmethane moiety enhanced the activity.

\section{Conclusion}

A new class of mono and bis heterocycles, sulfonylmethaneamido linked oxazoles, thiazoles, imidazoles, pyrrolyl oxazoles, pyrrolyl thiazoles and pyrrolyl imidazoles were prepared adopting simple, and versatile synthetic methodologies. The compound imidazolyl styrylsulfonylacetamide is the most potent antimicrobial agent.

\section{Experimental}

Melting points were determined in open capillaries on a 







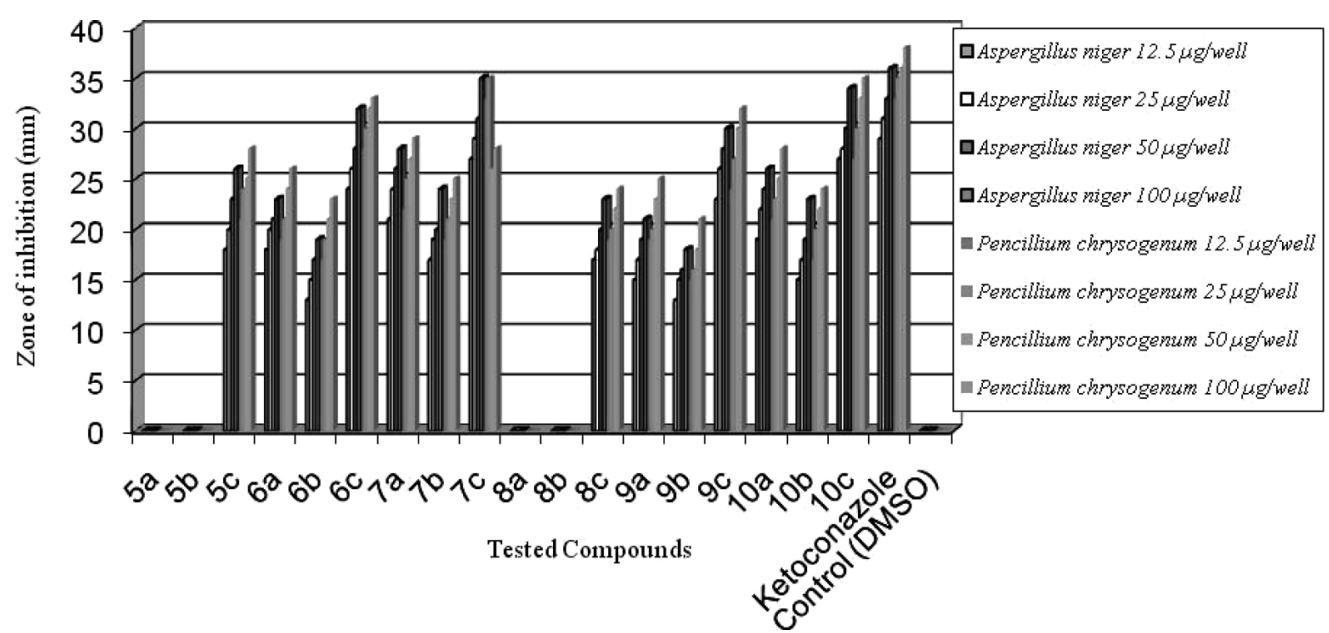

Fig. 2. The in-Vitro Antifungal Activity of Compounds 5-10

Table 2. The in-Vitro Antifungal Activity of Compounds 5-10

\begin{tabular}{|c|c|c|c|c|c|c|c|c|}
\hline \multirow{3}{*}{ Compound } & \multicolumn{8}{|c|}{ Zone of inhibition (mm) } \\
\hline & \multicolumn{4}{|c|}{ Aspergillus niger } & \multicolumn{4}{|c|}{ Penicillium chrysogenum } \\
\hline & $12.5 \mu \mathrm{g} /$ well & $25 \mu \mathrm{g} /$ well & $50 \mu \mathrm{g} /$ well & $100 \mu \mathrm{g} /$ well & $12.5 \mu \mathrm{g} /$ well & $25 \mu \mathrm{g} /$ well & $50 \mu \mathrm{g} /$ well & $100 \mu \mathrm{g} /$ well \\
\hline $5 a$ & - & - & - & - & - & - & - & - \\
\hline $5 \mathbf{b}$ & - & - & - & - & - & - & - & - \\
\hline $5 c$ & $18 \pm 4$ & $20 \pm 3$ & $23 \pm 2$ & $26 \pm 7$ & $21 \pm 2$ & $24 \pm 4$ & $25 \pm 5$ & $28 \pm 3$ \\
\hline $6 a$ & $18 \pm 5$ & $20 \pm 1$ & $21 \pm 6$ & $23 \pm 4$ & $19 \pm 2$ & $21 \pm 1$ & $24 \pm 3$ & $26 \pm 7$ \\
\hline $6 \mathbf{b}$ & $13 \pm 1$ & $15 \pm 2$ & $17 \pm 3$ & $19 \pm 7$ & $17 \pm 2$ & $19 \pm 1$ & $21 \pm 4$ & $23 \pm 5$ \\
\hline $6 c$ & $24 \pm 5$ & $26 \pm 2$ & $28 \pm 4$ & $32 \pm 3$ & $28 \pm 2$ & $30 \pm 1$ & $32 \pm 4$ & $33 \pm 5$ \\
\hline $7 \mathbf{a}$ & $21 \pm 1$ & $24 \pm 5$ & $26 \pm 7$ & $28 \pm 2$ & $22 \pm 3$ & $25 \pm 2$ & $27 \pm 1$ & $29 \pm 4$ \\
\hline $7 \mathbf{b}$ & $17 \pm 3$ & $19 \pm 1$ & $20 \pm 5$ & $24 \pm 2$ & $19 \pm 5$ & $21 \pm 2$ & $23 \pm 1$ & $25 \pm 4$ \\
\hline $7 c$ & $27 \pm 4$ & $29 \pm 1$ & $31 \pm 3$ & $35 \pm 7$ & $33 \pm 5$ & $35 \pm 7$ & $36 \pm 6$ & $38 \pm 3$ \\
\hline $8 a$ & - & - & - & - & - & - & - & - \\
\hline $8 b$ & - & - & - & - & - & - & - & - \\
\hline $8 c$ & $17 \pm 3$ & $18 \pm 2$ & $20 \pm 1$ & $23 \pm 7$ & $19 \pm 7$ & $20 \pm 4$ & $22 \pm 2$ & $24 \pm 1$ \\
\hline 9a & $15 \pm 6$ & $17 \pm 2$ & $19 \pm 5$ & $21 \pm 4$ & $19 \pm 3$ & $20 \pm 4$ & $23 \pm 5$ & $25 \pm 1$ \\
\hline $9 b$ & $13 \pm 2$ & $15 \pm 3$ & $16 \pm 6$ & $18 \pm 1$ & $15 \pm 3$ & $16 \pm 4$ & $18 \pm 2$ & $21 \pm 1$ \\
\hline $9 \mathrm{c}$ & $23 \pm 2$ & $26 \pm 1$ & $28 \pm 3$ & $30 \pm 5$ & $24 \pm 7$ & $27 \pm 4$ & $30 \pm 6$ & $32 \pm 2$ \\
\hline $10 \mathrm{a}$ & $19 \pm 4$ & $22 \pm 1$ & $24 \pm 2$ & $26 \pm 3$ & $21 \pm 1$ & $23 \pm 3$ & $25 \pm 5$ & $28 \pm 6$ \\
\hline $10 \mathrm{~b}$ & $15 \pm 4$ & $17 \pm 5$ & $19 \pm 2$ & $23 \pm 3$ & $17 \pm 7$ & $20 \pm 1$ & $22 \pm 2$ & $24 \pm 7$ \\
\hline $10 \mathrm{c}$ & $27 \pm 1$ & $28 \pm 4$ & $30 \pm 2$ & $34 \pm 5$ & $27 \pm 4$ & $30 \pm 2$ & $33 \pm 1$ & $35 \pm 6$ \\
\hline Ketoconazole & $29 \pm 1$ & $31 \pm 6$ & $33 \pm 4$ & $36 \pm 3$ & $33 \pm 3$ & $35 \pm 1$ & $36 \pm 2$ & $38 \pm 3$ \\
\hline Control (DMSO) & - & - & - & - & - & - & - & - \\
\hline
\end{tabular}

(-) No activity. ( \pm ) Standard deviation.

Table 3. MIC, MBC and MFC of Compounds 7e and 10c

\begin{tabular}{ccccccc}
\hline \hline \multirow{2}{*}{ Compound } & \multicolumn{5}{c}{ Minimum inhibitory concentration MIC (MBC/MFC) $\mu \mathrm{g}$} \\
\cline { 2 - 6 } & $\begin{array}{c}\text { Staphylococcus } \\
\text { aureus }\end{array}$ & $\begin{array}{c}\text { Bacillus } \\
\text { subtilis }\end{array}$ & $\begin{array}{c}\text { Pseudomonas } \\
\text { aeruginosa }\end{array}$ & $\begin{array}{c}\text { Klebsiella } \\
\text { pneumoniae }\end{array}$ & $\begin{array}{c}\text { Aspergillus } \\
\text { niger }\end{array}$ & $\begin{array}{c}\text { Penicillium } \\
\text { chrysogenum }\end{array}$ \\
\hline $\mathbf{7 c}$ & $12.5(50)$ & $12.5(25)$ & $12.5(25)$ & $25(100)$ & $12.5(50)$ & $12.5(25)$ \\
10c & $25(100)$ & $12.5(50)$ & $25(100)$ & $50(200)$ & $12.5(50)$ & $25(100)$ \\
Chloramphenicol & 6.25 & 6.25 & 6.25 & 12.5 & - & 6.25 \\
Ketoconazole & - & - & - & - & 12.5 \\
\hline
\end{tabular}

(一) No activity.

Mel-Temp apparatus and are uncorrected. The purity of the compounds was checked by TLC (silica gel H, BDH, ethyl acetate-hexane, 1:3). The IR spectra were recorded on a
Thermo Nicolet IR 200 FT-IR spectrometer as $\mathrm{KBr}$ pellets and the wavenumbers were given in $\mathrm{cm}^{-1}$. The ${ }^{1} \mathrm{H}-\mathrm{NMR}$ spectra were recorded in DMSO- $d_{6}$ on a Bruker- 400 spectrometer 
(400 MHz). The ${ }^{13} \mathrm{C}-\mathrm{NMR}$ spectra were recorded in DMSO- $d_{6}$ on a Bruker spectrometer operating at $100 \mathrm{MHz}$. All chemical shifts are reported in $\delta(\mathrm{ppm})$ using tetramethylsilane as an internal standard. The microanalyses were performed on a Perkin-Elmer 240C elemental analyzer. The compounds 4-aryloxazol-2-amine ${ }^{43)}$ (1), 4-arylthiazol-2-amine ${ }^{43)}$ (2), 4-aryl-1H-imidazol-2-amine ${ }^{44)}(3)$ and $Z$-(arylethenesulfonyl)acetic $\operatorname{acid}^{45)}$ required as the starting materials were prepared by adopting the literature precedent.

General Procedure for the Synthesis of $Z$ (Arylethenesulfonyl)acetyl Chloride $(4 a-c)$ To the compound Z-(arylethenesulfonyl)acetic $\operatorname{acid}^{45}$ ( $\left.3 \mathrm{mmol}\right)$, thionyl chloride ( $5 \mathrm{mmol}$ ) was added and refluxed for $30-45 \mathrm{~min}$. The excess thionyl chloride was removed by vacuum distillation and the residue was poured onto crushed ice. The separated solid was collected by filtration, washed with water, dried and recrystallized from ethanol.

Z-(Phenylethenesulfonyl)acetyl Chloride (4a): White solid, yield $82 \%, \mathrm{mp} 126-128^{\circ} \mathrm{C} ;{ }^{1} \mathrm{H}-\mathrm{NMR}$ (DMSO- $d_{6}$ ) $\delta: 4.83$ (s, $\left.2 \mathrm{H}, \mathrm{SO}_{2}-\mathrm{CH}_{2}\right), 6.46\left(\mathrm{~d}, 1 \mathrm{H}, \mathrm{H}_{\mathrm{B}}, J=9.3 \mathrm{~Hz}\right), 7.14-7.62(\mathrm{~m}, 6 \mathrm{H}$, $\left.\mathrm{H}_{\mathrm{A}}, \mathrm{Ar}-\mathrm{H}\right) .{ }^{13} \mathrm{C}-\mathrm{NMR}\left(\mathrm{DMSO}-d_{6}\right) \delta: 56.1\left(\mathrm{SO}_{2}-\mathrm{CH}_{2}\right), 121.5$ $\left(\mathrm{C}-\mathrm{H}_{\mathrm{B}}\right), 143.8\left(\mathrm{C}-\mathrm{H}_{\mathrm{A}}\right), 172.1(\mathrm{C}=\mathrm{O}), 125.3,126.9,127.7,133.3$ (aromatic carbons). IR $(\mathrm{KBr}) \mathrm{cm}^{-1}: 1748(\mathrm{C}=\mathrm{O}), 1634(\mathrm{C}=\mathrm{C})$, 1337, $1134\left(\mathrm{SO}_{2}\right)$.

Z-(4-Methylphenylethenesulfonyl)acetyl Chloride (4b): White solid, yield $84 \%, \mathrm{mp} 112-114^{\circ} \mathrm{C}$; ${ }^{1} \mathrm{H}-\mathrm{NMR}$ (DMSO$\left.d_{6}\right) \delta: 2.29\left(\mathrm{~s}, 3 \mathrm{H}, \mathrm{Ar}-\mathrm{CH}_{3}\right), 4.78\left(\mathrm{~s}, 2 \mathrm{H}, \mathrm{SO}_{2}-\mathrm{CH}_{2}\right), 6.45(\mathrm{~d}$, $\left.1 \mathrm{H}, \mathrm{H}_{\mathrm{B}}, J=9.2 \mathrm{~Hz}\right), 7.06-7.60\left(\mathrm{~m}, 5 \mathrm{H}, \mathrm{H}_{\mathrm{A}}, \mathrm{Ar}-\mathrm{H}\right) .{ }^{13} \mathrm{C}-\mathrm{NMR}$ $\left(\mathrm{DMSO}-d_{6}\right) \delta: 21.2\left(\mathrm{Ar}-\mathrm{CH}_{3}\right), 55.6\left(\mathrm{SO}_{2}-\mathrm{CH}_{2}\right), 120.3\left(\mathrm{C}-\mathrm{H}_{\mathrm{B}}\right)$, $143.6\left(\mathrm{C}-\mathrm{H}_{\mathrm{A}}\right), 172.0(\mathrm{C}=\mathrm{O}), 125.1,126.4,127.3,132.1$ (aromatic carbons). IR $(\mathrm{KBr}) \mathrm{cm}^{-1}: 1732(\mathrm{C}=\mathrm{O}), 1631(\mathrm{C}=\mathrm{C}), 1332$, $1129\left(\mathrm{SO}_{2}\right)$.

Z-(4-Chlorophenylethenesulfonyl)acetyl Chloride (4c): White solid, yield $85 \%, \mathrm{mp} 133-135^{\circ} \mathrm{C}$; ${ }^{1} \mathrm{H}-\mathrm{NMR}$ (DMSO- $d_{6}$ ) $\delta: 4.85\left(\mathrm{~s}, 2 \mathrm{H}, \mathrm{SO}_{2}-\mathrm{CH}_{2}\right), 6.47\left(\mathrm{~d}, 1 \mathrm{H}, \mathrm{H}_{\mathrm{B}}, J=9.5 \mathrm{~Hz}\right), 7.12-7.72$ $\left(\mathrm{m}, 5 \mathrm{H}, \mathrm{H}_{\mathrm{A}}, \mathrm{Ar}-\mathrm{H}\right) .{ }^{13} \mathrm{C}-\mathrm{NMR}\left(\mathrm{DMSO}-d_{6}\right) \delta: 56.2\left(\mathrm{SO}_{2}-\mathrm{CH}_{2}\right)$, $120.6\left(\mathrm{C}-\mathrm{H}_{\mathrm{B}}\right), 140.9\left(\mathrm{C}-\mathrm{H}_{\mathrm{A}}\right), 172.4(\mathrm{C}=\mathrm{O}), 126.9,127.8,128.2$, 134.9 (aromatic carbons). IR $(\mathrm{KBr}) \mathrm{cm}^{-1}: 1751(\mathrm{C}=\mathrm{O}), 1638$ $(\mathrm{C}=\mathrm{C}), 1341,1137\left(\mathrm{SO}_{2}\right)$.

General Procedure for the Synthesis of $Z$ (2-Arylethenesulfonyl)- $N$-(4-aryloxazol-2-yl)acetamide (5a-c), $\quad Z$-(2-Arylethenesulfonyl)- $N$-(4-arylthiazol-2-yl)acetamide $(6 \mathrm{a}-\mathrm{c})$ and $Z$-(2-Arylethenesulfonyl)- $\mathrm{N}$-(4aryl-1 $\boldsymbol{H}$-imidazol-2-yl)acetamide $(\mathbf{7 a}-\mathbf{c})$ The compound $\mathbf{4}$ (1.1 mmol), 1-3 $(1 \mathrm{mmol})$ and toluene $(1.5 \mathrm{~mL})$ were heated to reflux for $15-18 \mathrm{~h}$. The reaction mixture was cooled and was decolorized by treating it with 50:50 carbon-celite (v/v). The contents were passed through a pad of silica gel $(50 \mathrm{~mL})$ and eluted the product with $10 \%$ ethyl acetate-hexane. The crude product was then recrystallized from ethyl acetate-hexane.

$Z$-(2-Phenylethenesulfonyl)- $N$-(4-phenyloxazol-2-yl)acetamide (5a): Yellow solid, yield $73 \%$, mp $139-141^{\circ} \mathrm{C}$; ${ }^{1} \mathrm{H}-\mathrm{NMR}\left(\mathrm{DMSO}-d_{6}\right) \delta: 4.25\left(\mathrm{~s}, 2 \mathrm{H}, \mathrm{SO}_{2}-\mathrm{CH}_{2}\right), 6.47(\mathrm{~d}, 1 \mathrm{H}$, $\mathrm{H}_{\mathrm{B}}, J=9.4 \mathrm{~Hz}$ ), 7.12-7.72 (m, 12H, $\left.\mathrm{H}_{\mathrm{A}}, \mathrm{Ar}-\mathrm{H}, \mathrm{C}_{5}-\mathrm{H}\right), 7.95$ (br s, $1 \mathrm{H}, \mathrm{CO}-\mathrm{NH}) .{ }^{13} \mathrm{C}-\mathrm{NMR}\left(\mathrm{DMSO}-d_{6}\right) \delta: 57.6\left(\mathrm{SO}_{2}-\mathrm{CH}_{2}\right), 122.6$ $\left(\mathrm{C}-\mathrm{H}_{\mathrm{B}}\right), 135.2(\mathrm{C}-5), 138.2(\mathrm{C}-4), 141.5\left(\mathrm{C}-\mathrm{H}_{\mathrm{A}}\right), 149.1(\mathrm{C}-2)$, $171.6(\mathrm{C}=\mathrm{O}), 126.4,127.8,128.2,128.6,130.3,132.8,134.9$ (aromatic carbons). IR $(\mathrm{KBr}) \mathrm{cm}^{-1}: 3321(\mathrm{NH}), 1631(\mathrm{C}=\mathrm{O})$, $1628(\mathrm{C}=\mathrm{C}), 1576(\mathrm{C}=\mathrm{N}), 1332,1128\left(\mathrm{SO}_{2}\right) . \mathrm{MS} m / z: 368.42$ $\left(\mathrm{M}^{+}\right)$. Anal. Calcd for $\mathrm{C}_{19} \mathrm{H}_{16} \mathrm{~N}_{2} \mathrm{O}_{4} \mathrm{~S}: \mathrm{C}, 61.94 ; \mathrm{H}, 4.37 ; \mathrm{N}, 7.60$. Found: C, 61.82; H, 4.29; N, 7.73.
$Z$-(2 - (4 - Methylphenyl)ethenesulfonyl) - N-(4 - (4 methylphenyl)oxazol-2-yl)acetamide (5b): Yellow solid, yield $70 \%, \mathrm{mp} 125-127^{\circ} \mathrm{C} ;{ }^{1} \mathrm{H}-\mathrm{NMR}\left(\mathrm{DMSO}-d_{6}\right) \delta: 2.26$ and 2.29 $\left(\mathrm{s}, 6 \mathrm{H}, \mathrm{Ar}-\mathrm{CH}_{3}\right), 4.26\left(\mathrm{~s}, 2 \mathrm{H}, \mathrm{SO}_{2}-\mathrm{CH}_{2}\right), 6.45\left(\mathrm{~d}, 1 \mathrm{H}, \mathrm{H}_{\mathrm{B}}\right.$, $J=9.3 \mathrm{~Hz}$ ), $7.10-7.60\left(\mathrm{~m}, 10 \mathrm{H}, \mathrm{H}_{\mathrm{A}}, \mathrm{Ar}-\mathrm{H}, \mathrm{C}_{5}-\mathrm{H}\right), 7.93$ (br s, $1 \mathrm{H}$, CO-NH). ${ }^{13} \mathrm{C}-\mathrm{NMR}$ (DMSO- $\left.d_{6}\right) \delta: 21.6$ and $21.9\left(\mathrm{Ar}-\mathrm{CH}_{3}\right)$, $57.3\left(\mathrm{SO}_{2}-\mathrm{CH}_{2}\right), 121.4\left(\mathrm{C}-\mathrm{H}_{\mathrm{B}}\right), 134.9(\mathrm{C}-5), 138.0(\mathrm{C}-4), 140.9$ $\left(\mathrm{C}-\mathrm{H}_{\mathrm{A}}\right), 149.8(\mathrm{C}-2), 169.1(\mathrm{C}=\mathrm{O}), 126.2,127.2,128.3,130.1$, 131.9, 132.7, 133.1, 134.4 (aromatic carbons). IR $(\mathrm{KBr}) \mathrm{cm}^{-1}$ : $3317(\mathrm{NH}), 1660(\mathrm{C}=\mathrm{O}), 1621(\mathrm{C}=\mathrm{C}), 1571(\mathrm{C}=\mathrm{N}), 1330,1133$ $\left(\mathrm{SO}_{2}\right)$. Anal. Calcd for $\mathrm{C}_{21} \mathrm{H}_{20} \mathrm{~N}_{2} \mathrm{O}_{4} \mathrm{~S}$ : C, 63.61; H, 5.08; N, 7.06. Found: C, 63.70; H, 5.00; N, 7.14.

$Z$-(2-(4-Chlorophenyl)e thenesulfonyl) - N-(4-(4chlorophenyl)oxazol-2-yl)acetamide (5c): Yellow solid, yield $75 \%, \mathrm{mp} 162-164^{\circ} \mathrm{C}$; ${ }^{1} \mathrm{H}-\mathrm{NMR}$ (DMSO- $\left.d_{6}\right) \delta: 4.23(\mathrm{~s}, 2 \mathrm{H}$, $\left.\mathrm{SO}_{2}-\mathrm{CH}_{2}\right), 6.51\left(\mathrm{~d}, 1 \mathrm{H}, \mathrm{H}_{\mathrm{B}}, J=9.5 \mathrm{~Hz}\right), 7.14-7.71\left(\mathrm{~m}, 10 \mathrm{H}, \mathrm{H}_{\mathrm{A}}\right.$, Ar-H, C $5-\mathrm{H}$ ), 7.96 (br s, 1H, CO-NH). ${ }^{13} \mathrm{C}-\mathrm{NMR}$ (DMSO-d ${ }_{6}$ ) $\delta$ : $57.8\left(\mathrm{SO}_{2}-\mathrm{CH}_{2}\right), 122.9\left(\mathrm{C}-\mathrm{H}_{\mathrm{B}}\right), 135.3(\mathrm{C}-5), 138.5(\mathrm{C}-4)$, $141.7\left(\mathrm{C}-\mathrm{H}_{\mathrm{A}}\right), 149.4(\mathrm{C}-2), 171.9(\mathrm{C}=\mathrm{O}), 125.9,128.4,128.9$, $130.0,131.7,132.6,134.4,137.3$ (aromatic carbons). IR (KBr) $\mathrm{cm}^{-1}: 3328(\mathrm{NH}), 1632(\mathrm{C}=\mathrm{O}), 1631(\mathrm{C}=\mathrm{C}), 1578(\mathrm{C}=\mathrm{N})$, 1335, $1126\left(\mathrm{SO}_{2}\right)$. Anal. Calcd for $\mathrm{C}_{21} \mathrm{H}_{20} \mathrm{~N}_{2} \mathrm{O}{ }_{4} \mathrm{~S}: \mathrm{C}, 63.61 ; \mathrm{H}$, 5.08; N, 7.06. Found: C, 63.70; H, 5.00; N, 7.14.

$Z$-(2-Phenylethenesulfonyl)- $N$-(4-phenylthiazol-2-yl)acetamide (6a): Yellow solid, yield $68 \%$, mp $144-146^{\circ} \mathrm{C}$; ${ }^{1} \mathrm{H}-\mathrm{NMR}\left(\mathrm{DMSO}-d_{6}\right) \delta: 4.22\left(\mathrm{~s}, 2 \mathrm{H}, \mathrm{SO}_{2}-\mathrm{CH}_{2}\right), 6.34(\mathrm{~s}, 1 \mathrm{H}$, $\left.\mathrm{C}_{5}-\mathrm{H}\right), 6.46\left(\mathrm{~d}, 1 \mathrm{H}, \mathrm{H}_{\mathrm{B}}, J=9.6 \mathrm{~Hz}\right), 7.10-7.63\left(\mathrm{~m}, 11 \mathrm{H}, \mathrm{H}_{\mathrm{A}}\right.$, Ar-H), 7.91 (br s, 1H, CO-NH). ${ }^{13} \mathrm{C}-\mathrm{NMR}\left(\mathrm{DMSO}-d_{6}\right) \delta: 56.9$ $\left(\mathrm{SO}_{2}-\mathrm{CH}_{2}\right), 121.0\left(\mathrm{C}-\mathrm{H}_{\mathrm{B}}\right), 122.6(\mathrm{C}-5), 141.1\left(\mathrm{C}-\mathrm{H}_{\mathrm{A}}\right), 143.2$ (C-4), 156.8 (C-2), $169.7(\mathrm{C}=\mathrm{O}), 126.8,128.1,128.7,129.1$, 129.5, 133.1, 133.8, 135.2 (aromatic carbons). IR (KBr) cm$~^{-1}$ : $3326(\mathrm{NH}), 1648(\mathrm{C}=\mathrm{O}), 1634(\mathrm{C}=\mathrm{C}), 1565(\mathrm{C}=\mathrm{N}), 1322,1142$ $\left(\mathrm{SO}_{2}\right)$. MS m/z: $384.48\left(\mathrm{M}^{+}\right)$. Anal. Calcd for $\mathrm{C}_{19} \mathrm{H}_{16} \mathrm{~N}_{2} \mathrm{O}_{3} \mathrm{~S}_{2}: \mathrm{C}$, 59.35; H, 4.19; N, 7.28. Found: C, 59.47; H, 4.09; N, 7.37.

$Z$-(2-(4-Methylphenyl)e thenesulfonyl) - N-(4 - (4 methylphenyl)thiazol-2-yl)acetamide (6b): Yellow solid, yield $66 \%, \mathrm{mp} 135-137^{\circ} \mathrm{C}$; ${ }^{1} \mathrm{H}-\mathrm{NMR}$ (DMSO- $d_{6}$ ) $\delta: 2.24$ and 2.26 (s, 6H, Ar- $\left.\mathrm{CH}_{3}\right), 4.20\left(\mathrm{~s}, 2 \mathrm{H}, \mathrm{SO}_{2}-\mathrm{CH}_{2}\right), 6.33\left(\mathrm{~s}, 1 \mathrm{H}, \mathrm{C}_{5}-\mathrm{H}\right)$, $6.43\left(\mathrm{~d}, 1 \mathrm{H}, \mathrm{H}_{\mathrm{B}}, J=9.4 \mathrm{~Hz}\right), 7.07-7.58\left(\mathrm{~m}, 9 \mathrm{H}, \mathrm{H}_{\mathrm{A}}, \mathrm{Ar}-\mathrm{H}\right), 7.88$ (br s, $1 \mathrm{H}, \mathrm{CO}-\mathrm{NH}$ ). ${ }^{13} \mathrm{C}-\mathrm{NMR}$ (DMSO-d $\left.d_{6}\right) \delta: 21.3$ and 21.6 $\left(\mathrm{Ar}-\mathrm{CH}_{3}\right), 55.7\left(\mathrm{SO}_{2}-\mathrm{CH}_{2}\right), 121.7\left(\mathrm{C}-\mathrm{H}_{\mathrm{B}}\right), 122.1(\mathrm{C}-5), 140.8$ $\left(\mathrm{C}-\mathrm{H}_{\mathrm{A}}\right), 142.0(\mathrm{C}-4), 155.5(\mathrm{C}-2), 170.2(\mathrm{C}=\mathrm{O}), 126.5,127.8$, 128.0, 128.9, 129.7, 130.1, 132.7, 133.8 (aromatic carbons). IR $(\mathrm{KBr}) \mathrm{cm}^{-1}: 3324(\mathrm{NH}), 1640(\mathrm{C}=\mathrm{O}), 1627(\mathrm{C}=\mathrm{C}), 1581(\mathrm{C}=$ $\mathrm{N}), 1324,1147\left(\mathrm{SO}_{2}\right)$. Anal. Calcd for $\mathrm{C}_{21} \mathrm{H}_{20} \mathrm{~N}_{2} \mathrm{O}_{3} \mathrm{~S}_{2}:$ C, 61.14; H, 4.88; N, 6.78. Found: C, 61.06; H, 4.96; N, 6.69.

$Z$-(2-(4-Chlorophenyl)ethenesulfonyl) - N-(4 - (4 chlorophenyl)thiazol-2-yl)acetamide (6c): Yellow solid, yield $74 \%$, mp $188-189^{\circ} \mathrm{C}$; ${ }^{1} \mathrm{H}-\mathrm{NMR}$ (DMSO- $\left.d_{6}\right) \delta: 4.24$ (s, 2H, $\left.\mathrm{SO}_{2}-\mathrm{CH}_{2}\right), 6.36\left(\mathrm{~s}, 1 \mathrm{H}, \mathrm{C}_{5}-\mathrm{H}\right), 6.47\left(\mathrm{~d}, 1 \mathrm{H}, \mathrm{H}_{\mathrm{B}}, J=9.5 \mathrm{~Hz}\right)$, 7.11-7.66 (m, 9H, H $\mathrm{A}$, Ar-H), 7.92 (brs, 1H, CO-NH). ${ }^{13} \mathrm{C}-\mathrm{NMR} \quad\left(\mathrm{DMSO}-d_{6}\right) \quad \delta: \quad 57.1 \quad\left(\mathrm{SO}_{2}-\mathrm{CH}_{2}\right), 121.1 \quad\left(\mathrm{C}-\mathrm{H}_{\mathrm{B}}\right)$, $122.5(\mathrm{C}-5), 141.3\left(\mathrm{C}-\mathrm{H}_{\mathrm{A}}\right), 143.6(\mathrm{C}-4), 156.9(\mathrm{C}-2), 170.6$ $(\mathrm{C}=\mathrm{O}), 127.1,127.9,128.5,129.3,130.2,131.4,133.8,137.7$ (aromatic carbons). IR $(\mathrm{KBr}) \mathrm{cm}^{-1}: 3332(\mathrm{NH}), 1649(\mathrm{C}=\mathrm{O})$, $1634(\mathrm{C}=\mathrm{C}), 1583(\mathrm{C}=\mathrm{N}), 1327,1126\left(\mathrm{SO}_{2}\right)$. Anal. Calcd for $\mathrm{C}_{19} \mathrm{H}_{14} \mathrm{Cl}_{2} \mathrm{~N}_{2} \mathrm{O}_{3} \mathrm{~S}_{2}$ : C, 50.33; H, 3.11; N, 6.17. Found: C, 50.40; H, 3.18; N, 6.26.

$\mathrm{Z}$-(2-Phenylethenesulfonyl)- $\mathrm{N}$-(4-phenyl-1 $\mathrm{H}$-imidazol-2-yl)acetamide (7a): Yellow solid, yield $72 \%$, mp $167-169^{\circ} \mathrm{C}$; ${ }^{1} \mathrm{H}-\mathrm{NMR}\left(\mathrm{DMSO}-d_{6}\right) \delta: 4.25\left(\mathrm{~s}, 2 \mathrm{H}, \mathrm{SO}_{2}-\mathrm{CH}_{2}\right), 6.47(\mathrm{~d}, 1 \mathrm{H}$, 
$\mathrm{H}_{\mathrm{B}}, J=9.3 \mathrm{~Hz}$ ), 7.11-7.66 (m, 12H, $\left.\mathrm{H}_{\mathrm{A}}, \mathrm{Ar}-\mathrm{H}, \mathrm{C}_{5}-\mathrm{H}\right), 7.92$ (br s, $1 \mathrm{H}, \mathrm{CO}-\mathrm{NH}$ ), 12.26 (br s, $\left.1 \mathrm{H}, \mathrm{C}_{5}-\mathrm{NH}\right) .{ }^{13} \mathrm{C}-\mathrm{NMR}$ (DMSO- $d_{6}$ ) $\delta$ : $55.2\left(\mathrm{SO}_{2}-\mathrm{CH}_{2}\right), 122.3\left(\mathrm{C}-\mathrm{H}_{\mathrm{B}}\right), 134.5(\mathrm{C}-5), 136.8(\mathrm{C}-2)$, $140.3\left(\mathrm{C}-\mathrm{H}_{\mathrm{A}}\right), 142.1(\mathrm{C}-4), 170.1(\mathrm{C}=\mathrm{O}), 126.4,127.6,128.4$, 129.9, 131.3, 133.7, 134.8 (aromatic carbons). IR $(\mathrm{KBr}) \mathrm{cm}^{-1}$ : $3336(\mathrm{NH}), 1633(\mathrm{C}=\mathrm{O}), 1629(\mathrm{C}=\mathrm{C}), 1570(\mathrm{C}=\mathrm{N}), 1331,1135$ $\left(\mathrm{SO}_{2}\right)$. MS m/z: $367.43\left(\mathrm{M}^{+}\right)$. Anal. Calcd for $\mathrm{C}_{19} \mathrm{H}_{17} \mathrm{~N}_{3} \mathrm{O}_{3} \mathrm{~S}: \mathrm{C}$, 62.10; H, 4.66; N, 11.43. Found: C, 62.00; H, 4.72; N, 11.36.

$Z$-(2 - (4 - Methylphenyl)e thenesulfonyl)- N-(4 - (4 methylphenyl)-1H-imidazol-2-yl)acetamide (7b): Yellow solid, yield $65 \%, \mathrm{mp} 155-157^{\circ} \mathrm{C}$; ${ }^{1} \mathrm{H}-\mathrm{NMR}$ (DMSO- $d_{6}$ ) $\delta: 2.25$ and $2.28\left(\mathrm{~s}, 6 \mathrm{H}, \mathrm{Ar}-\mathrm{CH}_{3}\right), 4.22\left(\mathrm{~s}, 2 \mathrm{H}, \mathrm{SO}_{2}-\mathrm{CH}_{2}\right), 6.45\left(\mathrm{~d}, 1 \mathrm{H}, \mathrm{H}_{\mathrm{B}}\right.$, $J=9.7 \mathrm{~Hz}), 7.09-7.63\left(\mathrm{~m}, 10 \mathrm{H}, \mathrm{H}_{\mathrm{A}}, \mathrm{Ar}-\mathrm{H}, \mathrm{C}_{5}-\mathrm{H}\right), 7.91$ (br s, $1 \mathrm{H}, \mathrm{CO}-\mathrm{NH}$ ), 12.15 (br s, $1 \mathrm{H}, \mathrm{C}_{5}-\mathrm{NH}$ ). ${ }^{13} \mathrm{C}-\mathrm{NMR}$ (DMSO$\left.d_{6}\right) \delta$ : 21.4 and $21.6\left(\mathrm{Ar}-\mathrm{CH}_{3}\right), 57.0\left(\mathrm{SO}_{2}-\mathrm{CH}_{2}\right), 122.1\left(\mathrm{C}-\mathrm{H}_{\mathrm{B}}\right)$, $132.2(\mathrm{C}-5), 136.6(\mathrm{C}-2), 141.0\left(\mathrm{C}-\mathrm{H}_{\mathrm{A}}\right), 141.7(\mathrm{C}-4), 169.6$ $(\mathrm{C}=\mathrm{O}), 125.6,126.8,127.2,127.9,128.7,130.4,132.2,133.6$ (aromatic carbons). IR (KBr) $\mathrm{cm}^{-1}: 3229(\mathrm{NH}), 1628(\mathrm{C}=\mathrm{O})$, $1630(\mathrm{C}=\mathrm{C}), 1586(\mathrm{C}=\mathrm{N}), 1334,1126\left(\mathrm{SO}_{2}\right)$. Anal. Calcd for $\mathrm{C}_{21} \mathrm{H}_{21} \mathrm{~N}_{3} \mathrm{O}_{3} \mathrm{~S}$ : C, 63.77; H, 5.35; N, 10.62. Found: C, 63.88; H, $5.42 ; \mathrm{N}, 10.74$.

$Z$-(2 - (4 - Chlorophenyl)e thenesulfonyl) - N-(4 - (4 chlorophenyl)-1H-imidazol-2-yl)acetamide (7c): Yellow solid, yield $70 \%$; mp $192-194^{\circ} \mathrm{C}$; ${ }^{1} \mathrm{H}-\mathrm{NMR}$ (DMSO-d $\left.d_{6}\right) \delta: 4.26(\mathrm{~s}$, $\left.2 \mathrm{H}, \mathrm{SO}_{2}-\mathrm{CH}_{2}\right), 6.50\left(\mathrm{~d}, 1 \mathrm{H}, \mathrm{H}_{\mathrm{B}}, J=9.6 \mathrm{~Hz}\right), 7.13-7.67(\mathrm{~m}$, $10 \mathrm{H}, \mathrm{H}_{\mathrm{A}}, \mathrm{Ar}-\mathrm{H}, \mathrm{C}_{5}-\mathrm{H}$ ), 7.94 (br s, $1 \mathrm{H}, \mathrm{CO}-\mathrm{NH}$ ), 12.32 (br s, $\left.1 \mathrm{H}, \mathrm{C}_{5}-\mathrm{NH}\right) .{ }^{13} \mathrm{C}-\mathrm{NMR}\left(\mathrm{DMSO}-d_{6}\right) \delta: 57.5\left(\mathrm{SO}_{2}-\mathrm{CH}_{2}\right), 122.4$ $\left(\mathrm{C}-\mathrm{H}_{\mathrm{B}}\right), 134.7(\mathrm{C}-5), 137.1(\mathrm{C}-2), 140.6\left(\mathrm{C}-\mathrm{H}_{\mathrm{A}}\right), 142.3(\mathrm{C}-4)$, $170.7(\mathrm{C}=\mathrm{O}), 126.6,127.5,128.6,129.8,130.8,131.2,133.6$, 135.9 (aromatic carbons). IR $(\mathrm{KBr}) \mathrm{cm}^{-1}: 3242(\mathrm{NH}), 1642$ $(\mathrm{C}=\mathrm{O}), 1636(\mathrm{C}=\mathrm{C}), 1596(\mathrm{C}=\mathrm{N}), 1332,1124\left(\mathrm{SO}_{2}\right)$. Anal. Calcd for $\mathrm{C}_{19} \mathrm{H}_{15} \mathrm{Cl}_{2} \mathrm{~N}_{3} \mathrm{O}_{3} \mathrm{~S}$ : C, 52.30; H, 3.46; N, 9.63. Found: C, 52.41; H, 3.54; N, 9.50.

General Procedure for the Synthesis of $Z$-(4'-Aryl-1' $H$ pyrrol-3'-ylsulfonyl)- $N$-(4-aryloxazol-2-yl)acetamide $(8 \mathbf{a}-\mathbf{c})$, $Z$-(4'-Aryl-1' $H$-pyrrol-3'-ylsulfonyl)- $N$-(4-arylthiazol-2-yl)acetamide $(9 \mathrm{a}-\mathrm{c})$ and $Z$-(4'-Aryl-1' $H$-pyrrol-3'-ylsulfonyl)$\mathrm{N}$-(4-aryl-1H-imidazol-2-yl)acetamide $(\mathbf{1 0 a}-\mathrm{c})$ A mixture of tosylmethyl isocyanide $(1 \mathrm{mmol})$ and 5-7 $(1 \mathrm{mmol})$ in diethyl ether-DMSO $(2: 1)$ was added dropwise to a stirred mixture of sodium hydride $(0.05 \mathrm{~g})$ in dry diethyl ether $(10 \mathrm{~mL})$ at room temperature and stirring was continued for $12-14 \mathrm{~h}$. Then it was diluted with water and extracted with ether. The ethereal layer was dried (an. $\mathrm{Na}_{2} \mathrm{SO}_{4}$ ) and the solvent was removed under reduced pressure. The resultant solid was purified by passing through a column of silica gel (ethyl acetatehexane $1: 3)$ as eluent.

Z-(4'-Phenyl-1' H-pyrrol-3'-ylsulfonyl)- $N$-(4-phenyloxazol-2yl)acetamide (8a): Brown solid, yield $69 \%, \mathrm{mp} 146-148^{\circ} \mathrm{C}$; ${ }^{1} \mathrm{H}-\mathrm{NMR}\left(\mathrm{DMSO}-d_{6}\right) \delta: 4.32\left(\mathrm{~s}, 2 \mathrm{H}, \mathrm{SO}_{2}-\mathrm{CH}_{2}\right), 6.73(\mathrm{~s}, 1 \mathrm{H}$, $\left.\mathrm{C}_{5^{\prime}}-\mathrm{H}\right), 6.82\left(\mathrm{~s}, 1 \mathrm{H}, \mathrm{C}_{2^{\prime}}-\mathrm{H}\right), 7.18-7.82\left(\mathrm{~m}, 11 \mathrm{H}, \mathrm{Ar}-\mathrm{H}, \mathrm{C}_{5}-\mathrm{H}\right)$, 7.94 (br s, $1 \mathrm{H}, \mathrm{CO}-\mathrm{NH}$ ), 9.70 (br s, $\left.1 \mathrm{H}, \mathrm{C}_{2}, \mathrm{NH}\right) .{ }^{13} \mathrm{C}-\mathrm{NMR}$ $\left(\mathrm{DMSO}-d_{6}\right) \delta: 57.9\left(\mathrm{SO}_{2}-\mathrm{CH}_{2}\right), 113.2\left(\mathrm{C}-3^{\prime}\right), 115.6\left(\mathrm{C}-5^{\prime}\right), 123.2$ $\left(\mathrm{C}-2^{\prime}\right), 128.6\left(\mathrm{C}-4^{\prime}\right), 136.3$ (C-5), 138.8 (C-4), 149.5 (C-2), $172.2(\mathrm{C}=\mathrm{O}), 127.6,128.3,129.2,130.1,132.6,133.9,134.8$ (aromatic carbons). IR (KBr) $\mathrm{cm}^{-1}: 3228(\mathrm{NH}), 1683(\mathrm{C}=\mathrm{O})$, $1634(\mathrm{C}=\mathrm{C}), 1593(\mathrm{C}=\mathrm{N}), 1330,1133\left(\mathrm{SO}_{2}\right) . \mathrm{MS} m / z: 407.45$ $\left(\mathrm{M}^{+}\right)$. Anal. Calcd for $\mathrm{C}_{21} \mathrm{H}_{17} \mathrm{~N}_{3} \mathrm{O}_{4} \mathrm{~S}: \mathrm{C}, 61.90 ; \mathrm{H}, 4.20 ; \mathrm{N}$, 10.31. Found: C, 62.03; H, 4.28; N, 10.44.

$Z$-(4'-(4-Methylphenyl)-1' H-pyrrol-3'-ylsulfonyl)- $N$-(4-(4methylphenyl)oxazol-2-yl)acetamide (8b): Brown solid, yield
65\%, mp $143-145^{\circ} \mathrm{C} ;{ }^{1} \mathrm{H}-\mathrm{NMR}$ (DMSO-d $) \delta: 4.32(\mathrm{~s}, 2 \mathrm{H}$, $\left.\mathrm{SO}_{2}-\mathrm{CH}_{2}\right), 6.73\left(\mathrm{~s}, 1 \mathrm{H}, \mathrm{C}_{5^{\prime}}-\mathrm{H}\right), 6.82\left(\mathrm{~s}, 1 \mathrm{H}, \mathrm{C}_{2}, \mathrm{H}\right), 7.18-7.82$ (m, 11H, Ar-H, C ${ }_{5}-\mathrm{H}$ ), 7.94 (br s, 1H, CO-NH), 9.70 (br s, $\left.1 \mathrm{H}, \mathrm{C}_{2}, \mathrm{NH}\right) .{ }^{13} \mathrm{C}-\mathrm{NMR}\left(\mathrm{DMSO}-d_{6}\right) \delta: 57.9\left(\mathrm{SO}_{2}-\mathrm{CH}_{2}\right), 113.2$ $\left(\mathrm{C}-3^{\prime}\right), 115.6\left(\mathrm{C}-5^{\prime}\right), 123.2\left(\mathrm{C}-2^{\prime}\right), 128.6\left(\mathrm{C}-4^{\prime}\right), 136.3$ (C-5), 138.8 (C-4), 149.5 (C-2), $172.2(\mathrm{C}=\mathrm{O}), 127.6,128.3,129.2$, 130.1, 132.6, 133.9, 134.8 (aromatic carbons). IR $(\mathrm{KBr}) \mathrm{cm}^{-1}$ : $3224(\mathrm{NH}), 1675(\mathrm{C}=\mathrm{O}), 1632(\mathrm{C}=\mathrm{C}), 1576(\mathrm{C}=\mathrm{N}), 1334,1139$ $\left(\mathrm{SO}_{2}\right)$, Anal. Calcd for $\mathrm{C}_{23} \mathrm{H}_{21} \mathrm{~N}_{3} \mathrm{O}_{4} \mathrm{~S}: \mathrm{C}, 63.43 ; \mathrm{H}, 4.86 ; \mathrm{N}, 9.64$. Found: C, 63.34; H, 4.93; N, 9.76.

$Z$-(4'-(4-Chlorophenyl)1' H-pyrrol-3'-ylsulfonyl)- $N$-(4-(4chlorophenyl)oxazol-2-yl)acetamide (8c): Brown solid, yield $66 \%, \mathrm{mp} 174-176^{\circ} \mathrm{C}$; ${ }^{1} \mathrm{H}-\mathrm{NMR}$ (DMSO-d $) \delta: 4.35$ (s, $2 \mathrm{H}$, $\left.\mathrm{SO}_{2}-\mathrm{CH}_{2}\right), 6.75\left(\mathrm{~s}, 1 \mathrm{H}, \mathrm{C}_{5^{\prime}}-\mathrm{H}\right), 6.83\left(\mathrm{~s}, 1 \mathrm{H}, \mathrm{C}_{2^{\prime}}-\mathrm{H}\right), 7.32-7.88$ (m, 9H, Ar-H, C $-\mathrm{H}$ ), 7.95 (br s, 1H, CO-NH), 9.72 (br s, $\left.1 \mathrm{H}, \mathrm{C}_{2}, \mathrm{NH}\right) .{ }^{13} \mathrm{C}-\mathrm{NMR}\left(\mathrm{DMSO}-d_{6}\right) \delta: 58.1\left(\mathrm{SO}_{2}-\mathrm{CH}_{2}\right), 112.5$ $\left(\mathrm{C}-3^{\prime}\right), 115.7\left(\mathrm{C}-5^{\prime}\right), 123.0\left(\mathrm{C}-2^{\prime}\right), 128.9\left(\mathrm{C}-4^{\prime}\right), 136.5$ (C-5), 138.9 (C-4), 147.7 (C-2), $173.8(\mathrm{C}=\mathrm{O}), 127.8,128.4,128.9$, $129.3,130.3,132.2,135.6,136.3$ (aromatic carbons). IR ( $\mathrm{KBr})$ $\mathrm{cm}^{-1}: 3235(\mathrm{NH}), 1682(\mathrm{C}=\mathrm{O}), 1636(\mathrm{C}=\mathrm{C}), 1563(\mathrm{C}=\mathrm{N})$, 1332, $1124\left(\mathrm{SO}_{2}\right)$. Anal. Calcd for $\mathrm{C}_{21} \mathrm{H}_{15} \mathrm{Cl}_{2} \mathrm{~N}_{3} \mathrm{O}_{4} \mathrm{~S}$ : C, 52.95; H, 3.17; N, 8.82. Found: C, 53.04; H, 3.12; N, 8.74.

$Z$-(4'-Phenyl-1' H-pyrrol-3'-ylsulfonyl)- $N$-(4-phenylthiazol-2yl)acetamide (9a): Brown solid, yield $64 \%, \mathrm{mp} 149-151^{\circ} \mathrm{C}$; ${ }^{1} \mathrm{H}-\mathrm{NMR}\left(\mathrm{DMSO}-d_{6}\right) \delta$ : $4.28\left(\mathrm{~s}, 2 \mathrm{H}, \mathrm{SO}_{2}-\mathrm{CH}_{2}\right), 6.70(\mathrm{~s}, 1 \mathrm{H}$, $\left.\mathrm{C}_{5^{\prime}}-\mathrm{H}\right), 6.79\left(\mathrm{~s}, 1 \mathrm{H}, \mathrm{C}_{2}-\mathrm{H}\right), 7.15-7.74\left(\mathrm{~m}, 11 \mathrm{H}, \mathrm{Ar}-\mathrm{H}, \mathrm{C}_{5}-\mathrm{H}\right)$, 7.90 (br s, $1 \mathrm{H}, \mathrm{CO}-\mathrm{NH}$ ), 9.69 (br s, $\left.1 \mathrm{H}, \mathrm{C}_{2^{\prime}}-\mathrm{NH}\right) .{ }^{13} \mathrm{C}-\mathrm{NMR}$ $\left(\mathrm{DMSO}-d_{6}\right) \delta: 57.5\left(\mathrm{SO}_{2}-\mathrm{CH}_{2}\right), 110.6\left(\mathrm{C}-3^{\prime}\right), 115.1\left(\mathrm{C}-5^{\prime}\right), 121.8$ (C-5), 122.8 (C-2'), 128.2 (C-4'), 143.7 (C-4), 157.3 (C-2), 171.4 $(\mathrm{C}=\mathrm{O}), 127.3,128.1,129.5,130.6,132.5,133.3,134.9$ (aromatic carbons). IR (KBr) cm $\mathrm{cm}^{-1}: 3240(\mathrm{NH}), 1664(\mathrm{C}=\mathrm{O}), 1631(\mathrm{C}=$ C), $1578(\mathrm{C}=\mathrm{N}), 1333,1148\left(\mathrm{SO}_{2}\right)$. MS m/z: $423.51\left(\mathrm{M}^{+}\right)$. Anal. Calcd for $\mathrm{C}_{21} \mathrm{H}_{17} \mathrm{~N}_{3} \mathrm{O}_{3} \mathrm{~S}_{2}$ : C, 59.55; H, 4.04; N, 9.92. Found: $\mathrm{C}$, 59.62; H, 4.00; N, 9.85.

$Z$-(4'-(4-Methylphenyl)-1' $H$-pyrrol-3'-ylsulfonyl)- $N$-(4-(4methylphenyl)thiazol-2-yl)acetamide (9b): Brown solid, yield $66 \%, \mathrm{mp} 140-142^{\circ} \mathrm{C} ;{ }^{1} \mathrm{H}-\mathrm{NMR}$ (DMSO- $d_{6}$ ) $\delta: 2.23$ and 2.26 (s, 6H, Ar- $\left.\mathrm{CH}_{3}\right), 4.25$ (s, 2H, $\left.\mathrm{SO}_{2}-\mathrm{CH}_{2}\right), 6.65\left(\mathrm{~s}, 1 \mathrm{H}, \mathrm{C}_{5^{\prime}}-\mathrm{H}\right)$, $6.78\left(\mathrm{~s}, 1 \mathrm{H}, \mathrm{C}_{2}-\mathrm{H}\right), 7.12-7.76\left(\mathrm{~m}, 9 \mathrm{H}, \mathrm{Ar}-\mathrm{H}, \mathrm{C}_{5}-\mathrm{H}\right), 7.86$ (br s, $1 \mathrm{H}, \mathrm{CO}-\mathrm{NH}$ ), 9.70 (br s, $\left.1 \mathrm{H}, \mathrm{C}_{2}, \mathrm{NH}\right) .{ }^{13} \mathrm{C}-\mathrm{NMR}$ (DMSO-d $)$ $\delta$ : 21.4 and $21.6\left(\mathrm{Ar}-\mathrm{CH}_{3}\right), 57.2\left(\mathrm{SO}_{2}-\mathrm{CH}_{2}\right), 108.8\left(\mathrm{C}-3^{\prime}\right), 114.5$ $\left(\mathrm{C}-5^{\prime}\right), 121.7$ (C-5), 122.5 (C-2'), 127.5 (C-4'), 143.4 (C-4), $156.1(\mathrm{C}-2), 171.1(\mathrm{C}=\mathrm{O}), 127.2,127.8,128.1,129.1,129.7$, 130.8, 132.5, 133.6 (aromatic carbons). IR (KBr) cm $\mathrm{cm}^{-1}: 3227$ $(\mathrm{NH}), 1656(\mathrm{C}=\mathrm{O}), 1630(\mathrm{C}=\mathrm{C}), 1571(\mathrm{C}=\mathrm{N}), 1336,1141$ $\left(\mathrm{SO}_{2}\right)$. Anal. Calcd for $\mathrm{C}_{23} \mathrm{H}_{21} \mathrm{~N}_{3} \mathrm{O}_{3} \mathrm{~S}_{2}: \mathrm{C}, 61.17 ; \mathrm{H}, 4.68 ; \mathrm{N}$, 9.30. Found: C, 61.24; H, 4.75; N, 9.41.

$\mathrm{Z}$-(4'-(4-Chlorophenyl)-1' H-pyrrol-3'-ylsulfonyl)- $\mathrm{N}$-(4-(4chlorophenyl)thiazol-2-yl)acetamide (9c): Brown solid, yield $71 \%$, mp $193-195^{\circ} \mathrm{C}$; ${ }^{1} \mathrm{H}-\mathrm{NMR}$ (DMSO-d $\left.d_{6}\right) \delta: 4.29(\mathrm{~s}, 2 \mathrm{H}$, $\left.\mathrm{SO}_{2}-\mathrm{CH}_{2}\right), 6.63\left(\mathrm{~s}, 1 \mathrm{H}, \mathrm{C}_{5^{\prime}}-\mathrm{H}\right), 6.81\left(\mathrm{~s}, 1 \mathrm{H}, \mathrm{C}_{2^{\prime}}-\mathrm{H}\right), 7.21-7.78$ (m, 9H, Ar-H, C $-\mathrm{H}$ ), 7.92 (br s, 1H, CO-NH), 9.68 (br s, $\left.1 \mathrm{H}, \mathrm{C}_{2}, \mathrm{NH}\right) .{ }^{13} \mathrm{C}-\mathrm{NMR}\left(\mathrm{DMSO}-d_{6}\right) \delta: 57.8\left(\mathrm{SO}_{2}-\mathrm{CH}_{2}\right), 111.2$ $\left(\mathrm{C}-3^{\prime}\right), 115.3\left(\mathrm{C}-5^{\prime}\right), 122.1(\mathrm{C}-5), 123.1\left(\mathrm{C}-2^{\prime}\right), 128.3\left(\mathrm{C}-4^{\prime}\right)$, 144.0 (C-4), 157.5 (C-2), $171.8(\mathrm{C}=\mathrm{O}), 127.5,128.6,129.1$, $129.9,131.1,131.8,133.4,137.3$ (aromatic carbons). IR (KBr) $\mathrm{cm}^{-1}: 3243(\mathrm{NH}), 1674(\mathrm{C}=\mathrm{O}), 1632(\mathrm{C}=\mathrm{C}), 1568(\mathrm{C}=\mathrm{N})$, 1335, $1133\left(\mathrm{SO}_{2}\right)$. Anal. Calcd for $\mathrm{C}_{21} \mathrm{H}_{15} \mathrm{Cl}_{2} \mathrm{~N}_{3} \mathrm{O}_{3} \mathrm{~S}_{2}$ : C, 51.22; H, 3.07; N, 8.53. Found: C, 51.33; H, 3.00; N, 8.62.

$Z$-(4'-Phenyl-1' $H$-pyrrol-3'-ylsulfonyl)- $N$-(4-phenyl- $1 H$ imidazol-2-yl)acetamide (10a): Brown solid, yield 64\%, mp 
175-177 ${ }^{\circ}$; ${ }^{1} \mathrm{H}-\mathrm{NMR}\left(\mathrm{DMSO}-d_{6}\right) \delta: 4.26\left(\mathrm{~s}, 2 \mathrm{H}, \mathrm{SO}_{2}-\mathrm{CH}_{2}\right)$, $6.71\left(\mathrm{~s}, 1 \mathrm{H}, \mathrm{C}_{5^{\prime}}-\mathrm{H}\right), 6.80\left(\mathrm{~s}, 1 \mathrm{H}, \mathrm{C}_{2^{\prime}}-\mathrm{H}\right), 7.16-7.81(\mathrm{~m}, 11 \mathrm{H}$, Ar-H, $\mathrm{C}_{5}-\mathrm{H}$ ), 7.91 (br s, 1H, CO-NH), 9.71 (br s, $1 \mathrm{H}, \mathrm{C}_{2^{\prime}}-\mathrm{NH}$ ), 12.46 (br s, $\left.1 \mathrm{H}, \mathrm{C}_{5}-\mathrm{NH}\right) .{ }^{13} \mathrm{C}-\mathrm{NMR}\left(\mathrm{DMSO}-d_{6}\right) \delta: 55.6\left(\mathrm{SO}_{2}-\right.$ $\left.\mathrm{CH}_{2}\right), 111.8\left(\mathrm{C}-3^{\prime}\right), 115.2\left(\mathrm{C}-5^{\prime}\right), 123.0\left(\mathrm{C}-2^{\prime}\right), 128.3\left(\mathrm{C}-4^{\prime}\right)$, 134.8 (C-5), 137.3 (C-2), 143.1 (C-4), $171.8(\mathrm{C}=\mathrm{O}), 127.5$, $128.2,129.6,130.8,131.4,133.9,134.7$ (aromatic carbons). IR $(\mathrm{KBr}) \mathrm{cm}^{-1}: 3273(\mathrm{NH}), 1684(\mathrm{C}=\mathrm{O}), 1628(\mathrm{C}=\mathrm{C}), 1577(\mathrm{C}=$ $\mathrm{N}), 1332,1152\left(\mathrm{SO}_{2}\right)$. MS m/z: $406.47\left(\mathrm{M}^{+}\right)$. Anal. Calcd for $\mathrm{C}_{21} \mathrm{H}_{18} \mathrm{~N}_{4} \mathrm{O}_{3} \mathrm{~S}$ : C, 62.05; H, 4.46; N, 13.78. Found: C, 62.14; H, $4.51 ; \mathrm{N}, 13.64$.

$Z$-(4'-(4-Methylphenyl)-1' H-pyrrol-3'-ylsulfonyl)- $N$-(4-(4methylphenyl)-1H-imidazol-2-yl)acetamide (10b): Brown solid, yield $69 \%, \mathrm{mp} 182-184^{\circ} \mathrm{C} ;{ }^{1} \mathrm{H}-\mathrm{NMR}\left(\mathrm{DMSO}-d_{6}\right) \delta: 2.24$ and $2.28\left(\mathrm{~s}, 6 \mathrm{H}, \mathrm{Ar}-\mathrm{CH}_{3}\right), 4.28\left(\mathrm{~s}, 2 \mathrm{H}, \mathrm{SO}_{2}-\mathrm{CH}_{2}\right), 6.68(\mathrm{~s}, 1 \mathrm{H}$, $\left.\mathrm{C}_{5^{\prime}}-\mathrm{H}\right), 6.77\left(\mathrm{~s}, 1 \mathrm{H}, \mathrm{C}_{2^{\prime}}-\mathrm{H}\right), 7.14-7.80\left(\mathrm{~m}, 9 \mathrm{H}, \mathrm{Ar}-\mathrm{H}, \mathrm{C}_{5}-\mathrm{H}\right)$, 7.85 (br s, 1H, CO-NH), 9.65 (br s, $\left.1 \mathrm{H}, \mathrm{C}_{2}, \mathrm{NH}\right), 12.38$ (br s, $1 \mathrm{H}, \mathrm{C}_{5}-\mathrm{NH}$ ). ${ }^{13} \mathrm{C}-\mathrm{NMR}$ (DMSO- $d_{6}$ ) $\delta$ : 21.5 and 21.8 $\left(\mathrm{Ar}-\mathrm{CH}_{3}\right), 56.4\left(\mathrm{SO}_{2}-\mathrm{CH}_{2}\right), 111.2\left(\mathrm{C}-3^{\prime}\right), 114.9\left(\mathrm{C}-5^{\prime}\right), 121.8$ (C-2'), 127.6 (C-4'), 134.6 (C-5), 137.8 (C-2), 142.7 (C-4), 171.9 $(\mathrm{C}=\mathrm{O}), 127.1,128.6,128.9,129.5,130.7,132.9,133.4,134.9$ (aromatic carbons). IR (KBr) $\mathrm{cm}^{-1}: 3271(\mathrm{NH}), 1683(\mathrm{C}=\mathrm{O})$, $1626(\mathrm{C}=\mathrm{C}), 1567(\mathrm{C}=\mathrm{N}), 1337,1157\left(\mathrm{SO}_{2}\right)$. Anal. Calcd for $\mathrm{C}_{23} \mathrm{H}_{22} \mathrm{~N}_{4} \mathrm{O}_{3} \mathrm{~S}: \mathrm{C}, 63.57 ; \mathrm{H}, 5.10 ; \mathrm{N}, 12.89$. Found: C, 63.45; H, $5.02 ; \mathrm{N}, 12.99$.

$Z$-(4'-(4-Chlorophenyl)-1' H-pyrrol-3'-ylsulfonyl)- $N$-(4-(4chlorophenyl)- $1 H$-imidazol-2-yl)acetamide (10c): Brown solid, yield $72 \%, \mathrm{mp} 202-201^{\circ} \mathrm{C} ;{ }^{1} \mathrm{H}-\mathrm{NMR}$ (DMSO- $\left.d_{6}\right) \quad \delta: 4.25$ $\left(\mathrm{s}, 2 \mathrm{H}, \mathrm{SO}_{2}-\mathrm{CH}_{2}\right), 6.73\left(\mathrm{~s}, 1 \mathrm{H}, \mathrm{C}_{5^{\prime}}-\mathrm{H}\right), 6.82\left(\mathrm{~s}, 1 \mathrm{H}, \mathrm{C}_{2^{\prime}}-\mathrm{H}\right)$, 7.22-7.84 (m, 9H, Ar-H, C $5-\mathrm{H}), 7.94$ (br s, 1H, CO-NH), 9.71 (br s, $1 \mathrm{H}, \mathrm{C}_{2}, \mathrm{NH}$ ), 12.46 (br s, $1 \mathrm{H}, \mathrm{C}_{5}-\mathrm{NH}$ ). ${ }^{13} \mathrm{C}-\mathrm{NMR}$ $\left(\mathrm{DMSO}_{6}\right) \delta: 57.9\left(\mathrm{SO}_{2}-\mathrm{CH}_{2}\right), 112.3\left(\mathrm{C}-3^{\prime}\right), 115.4\left(\mathrm{C}-5^{\prime}\right), 123.4$ (C-2'), 127.0 (C-4'), 135.0 (C-5), 137.6 (C-2), 142.4 (C-4), 172.2 $(\mathrm{C}=\mathrm{O}), 126.6,127.8,128.4,128.9,129.3,130.8,134.0,137.1$ (aromatic carbons). IR (KBr) $\mathrm{cm}^{-1}: 3277(\mathrm{NH}), 1687(\mathrm{C}=\mathrm{O})$, $1629(\mathrm{C}=\mathrm{C}), 1582(\mathrm{C}=\mathrm{N}), 1334,1146\left(\mathrm{SO}_{2}\right)$. Anal. Calcd for $\mathrm{C}_{21} \mathrm{H}_{16} \mathrm{Cl}_{2} \mathrm{~N}_{4} \mathrm{O}_{3} \mathrm{~S}$ : C, 53.05; H, 3.39; N, 11.78. Found: C, 52.97; $\mathrm{H}, 3.32 ; \mathrm{N}, 11.65$.

Antimicrobial Testing The compounds 5-10 were dissolved in DMSO at different concentrations of 12.5, 25, 50 and $100 \mu \mathrm{g} /$ well. Bacterial strains Staphylococcus aureus, Bacillus subtilis, Pseudomonas aeruginosa, Klebsiella pneumoniae and fungi Aspergillus niger, Penicillium chrysogenum were obtained from Department of Microbiology, S.V. University, Tirupati.

Antibacterial and Antifungal Assays The in-vitro antimicrobial studies were carried out by agar well diffusion method against test organisms. ${ }^{46,47)}$ Nutrient broth (NB) plates were swabbed with $24 \mathrm{~h}$ old broth culture $(100 \mu \mathrm{L})$ of test bacteria. Using the sterile cork borer, wells $(6 \mathrm{~mm})$ were made into each petriplate. The compounds were dissolved in DMSO of $5 \mathrm{mg} / \mathrm{mL}$ and from this $2.5,5,10$, and $20 \mu \mathrm{L}(12.5,25,50$, $100 \mu \mathrm{g} /$ well) were added into the wells by using sterile pipettes. Simultaneously the standard antibiotics, chloramphenicol for antibacterial activity and ketoconazole for antifungal activity (as positive control) were tested against the pathogens. The samples were dissolved in DMSO which showed no zone of inhibition acts as negative control. The plates were incubated at $37^{\circ} \mathrm{C}$ for $24 \mathrm{~h}$ for bacteria and at $28^{\circ} \mathrm{C}$ for $48 \mathrm{~h}$ for fungi. After appropriate incubation, the diameter of zone of inhibition of each well was measured. Duplicates were main- tained and the average values were calculated for eventual antibacterial activity.

Broth dilution test was used to determine minimum inhibitory concentration (MIC) of the above mentioned samples. ${ }^{48,49)}$ Freshly prepared nutrient broth was used as diluents. The $24 \mathrm{~h}$ old culture of the test bacteria Staphylococcus aureus, Bacillus subtilis, Pseudomonas aeruginosa and Klebsiella pneumoniae and the test fungi Aspergillus niger and Penicillium chrysogenum were diluted 100 folds in nutrient broth $(100 \mu \mathrm{L}$ bacterial cultures in $10 \mathrm{~mL} \mathrm{NB})$. The stock solution of the synthesized compounds was prepared in DMSO by dissolving $5 \mathrm{mg}$ of the compound in $1 \mathrm{~mL}$ of DMSO. Increasing concentrations of the test samples $(1.25,2.5,5,10,20,40 \mu \mathrm{L}$ of stock solution contains $6.25,12.5,25,50,100,200 \mu \mathrm{g}$ of the compounds) were added to the test tubes containing the bacterial and fungal cultures. All the tubes were incubated at $37^{\circ} \mathrm{C}$ for $24 \mathrm{~h}$ for bacteria and at $28^{\circ} \mathrm{C}$ for $48 \mathrm{~h}$ for fungi. The tubes were examined for visible turbidity and using NB as control. Control without test samples and with solvent was assayed simultaneously. The lowest concentration that inhibited visible growth of the tested organisms was recorded as MIC. To determine the minimum bactericidal concentration $(\mathrm{MBC})^{50)}$ and minimum fungicidal concentration $(\mathrm{MFC})^{51)}$ for each set of test tubes in the MIC determination, a loopful of broth was collected from those tubes which did not show any growth and inoculated on sterile nutrient broth (for bacteria) and PDA (for fungi) by streaking. Plates inoculated with bacteria and fungi were incubated at $37^{\circ} \mathrm{C}$ for $24 \mathrm{~h}$ and at $28^{\circ} \mathrm{C}$ for $48 \mathrm{~h}$, respectively. After incubation, the lowest concentration was noted as MBC (for bacteria) or MFC (for fungi) at which no visible growth was observed.

Acknowledgements The Department of Science and Technology (DST), New Delhi, India is gratefully acknowledged for its financial support. One of the authors L. Mallikarjuna Reddy is thankful to CSIR, New Delhi, India for the sanction of Junior Research Fellowship.

\section{References}

1) Hughes R. A., Thompson S. P., Alcaraz L., Moody C. J., J. Am. Chem. Soc., 127, 15644-15651 (2005).

2) Glover C., Merritt E. A., Bagley M. C., Tetrahedron Lett., 48 , 7027-7030 (2007).

3) You S.-L., Kelly J. W., Tetrahedron, 61, 241-249 (2005).

4) You S.-L., Kelly J. W., Tetrahedron Lett., 46, 2567-2570 (2005).

5) Yokokawa F., Sameshima H., Shioiri T., Tetrahedron Lett., 42 4171-4174 (2001).

6) Pihko P. M., Koskinen A. M. P., J. Org. Chem., 63, 92-98 (1998).

7) Pathan M. Y., Paike V. V., Pachmase P. R., More S. P., Ardhapure S. S., Pawar R. P., ARKIVOC, 205-210 (2006).

8) Hantzch A., Ber. Dtsch. Chem. Ges, 21, 942-947 (1888).

9) Wiley R. H., England D. C., Behr L. C., "Organic Reactions," Vol. 6, John Wiley, 1951, pp. 367-409.

10) Robinson R., J. Chem. Soc., 95, 2167-2174 (1909).

11) Gabriel, Chem. Ber., 43, 1283-1287 (1910).

12) Gordon T. D., Singh J., Hansen P. E., Morgan B. A., Tetrahedron Lett., 34, 1901-1904 (1993).

13) Brain C. T., Paul J. M., Synlett, 1999, 1642-1644 (1999).

14) Morwick T., Hrapchak M., DeTuri M., Campbell S., Org. Lett., 4 2665-2668 (2002).

15) Roy S., Haque S., Gribble G. W., Synthesis, 3948-3954 (2006).

16) Cornforth J. W., Cornforth R. H., J. Chem. Soc., 96-102 (1947).

17) Shin C.-G., Sato Y., Sugiyama H., Nanjo K., Yoshimura J., Bull. 
Chem. Soc. Jpn., 50, 1788-1792 (1977).

18) Yokoyama M., Menjo Y., Watanabe M., Togo H., Synthesis, $1467-$ 1470 (1994).

19) Review on oxazolines: Gant T. G., Meyers A. I., Tetrahedron, 50, 2297-2360 (1994).

20) Evans D. L., Minster D. K., Jordis U., Hecht S. M., Mazzu A. L. Jr., Meyers A. I., J. Org. Chem., 44, 497-501 (1979).

21) Kashima C., Arao H., Synthesis, 873-874 (1989).

22) Barrish J. C., Singh J., Spergel S. H., Han W.-C., Kissick T. P., Kronenthal D. R., Mueller R. H., J. Org. Chem., 58, 4494-4496 (1993).

23) Wipf P., Miller C. P., J. Org. Chem., 58, 3604-3606 (1993).

24) Meyers A. I., Tavares F. X., J. Org. Chem., 61, 8207-8215 (1996).

25) Williams D. R., Lowder P. D., Gu Y.-G., Brooks D. A., Tetrahedron Lett., 38, 331-334 (1997).

26) Phillips A. J., Uto Y., Wipf P., Reno M. J., Williams D. R., Org. Lett., 2, 1165-1168 (2000).

27) Prager R. H., Smith J. A., Weber B., Williams C. M., J. Chem. Soc., Perkin Trans. I, 2659-2672 (1997).

28) Wang Z., "Comprehensive Organic Name Reactions and Reagents," John Wiley \& Sons, Inc., Hoboken, NJ, 2009, pp. 2293-2297.

29) Jones R. A., Bean G. P., "The Chemistry of Pyrroles," Academic, London, 1977.

30) Woo J., Sigurdsson S. T., Hopkins P. B., J. Am. Chem. Soc., 115, 3407-3415 (1993).

31) Cooney J. V., Mcewen W. E., J. Org. Chem., 46, 2570-2573 (1981).

32) Lee D., Swager T. M., J. Am. Chem. Soc., 125, 6870-6871 (2003).

33) Peschko C., Winklhofer C., Terpin A., Steglich W., Synthesis, 3048-3052 (2006).

34) Cheng L., Lightner D. A., Synthesis, 46-58 (1999).

35) Knorr L., Chem. Ber., 17, 1635-1642 (1884).

36) Patterson J. M., Synthesis, 281-304 (1976).
37) Bean G. P., "The Chemistry of Heterocyclic Compounds, Pyrroles," Vol. 48, ed. by Jones R. A., Wiley, New York, NY, 1990, p. 105.

38) Hantzsch A., Ber. Dtsch. Chem. Ges., 23, 1474-1483 (1890).

39) Plaskon A. S., Ryabukhin S. V., Volochnyuk D. M., Shivanyuk A. N., Tolmachev A. A., Tetrahedron, 64, 5933-5943 (2008).

40) Furstner A., Weintritt H., Hupperts A., J. Org. Chem., 60, 66376641 (1995).

41) Katritzky A., Jiang J., Steel P. J., J. Org. Chem., 59, 4551-4555 (1994).

42) Padmavathi V., Prema Kumari C., Venkatesh B. C., Padmaja A., Eur. J. Med. Chem., 46, 5317-5326 (2011).

43) Little T. L., Webber S. E., J. Org. Chem., 59, 7299-7305 (1994).

44) Potewar T. M., Ingale S. A., Srinivasan K. V., Tetrahedron, 64, 5019-5022 (2008).

45) Reddy M. V. R., Reddy N. S., Synthesis, 322-323 (1984).

46) Chung K. T., Thomasson W. R., Wu-Yuan C. D., J. Appl. Bacteriol., 69, 498-503 (1990).

47) Azoro C., World J. Biotechno, 3, 347-357 (2002).

48) Janovska D., Kubikova K., Kokoska L., J. Food Sci., 21, 107-110 (2003).

49) Bishnu J., Sunil L., Anuja S., J. Science. Eng. Technol., 5, 143-150 (2009).

50) Clinical and Laboratory Standards Institute, "Methods for dilution antimicrobial susceptibility tests for bacteria that grow aerobically, 7th edition; approved standard, CLSI Document M7-A7," Ways, Pennsylvania, 2006.

51) Clinical and Laboratory Standards Institute, "Method for broth dilution antifungal susceptibility testing of yeasts, approved standard NCCLS Document M27-A2," Ways, Pennsylvania, 2002. 